\title{
Monitorizarea saturației tisulare cerebrale la prematurul anemic
}

\author{
Mihaela Demetrian, Andreea Avramescu, Vlad Dima, Roxana Iliescu \\ Spitalul Clinic de Obstetrică şi Ginecologie „Filantropia“, Bucureşti, România
}

\begin{abstract}
REZUMAT
Obiective. În acest studiu, am investigat dacă măsurătorile NIRS înainte şi după transfuziile de concentrat eritrocitar pot răspunde la întrebarea: a reprezentat transfuzia un beneficiu? Pot fi utile măsurătorile derivate din NIRS în identificarea unor criterii mai obiective pentru ghidurile de transfuzie?

Material şi metodă. Studiu prospectiv, observaţional ce s-a derulat în perioada iulie 2017 - martie 2018 într-un centru terţiar de terapie intensivă. A înrolat 44 de prematuri cu greutatea $\leq 1.250 \mathrm{~g}$ şi vârstă gestaţională $\leq 30$ săptămâni, care au fost randomizaţi în funcţie de transfuzia de CE în grup transfuzat $(n=29)$ şi grup netransfuzat $(n=15)$. Prematurii care au necesitat transfuzie au fost monitorizaţi NIRS, pretransfuzional (monitorizare continuă 24 de ore), în timpul transfuziei, şi 24 de ore după transfuzie. Pacienţii netransfuzaţi au fost de asemenea monitorizaţi cu pulsoximetrie regională cerebrală la o vârstă postnatală şi în condiţii clinice asemănătoare grupului transfuzat.

Rezultate. Valorile oximetriei cerebrale şi sistemice au avut valori comparabile la cele cele două grupuri atunci când s-au comparat rezultatele dinaintea transfuziei.Legat de efectul transfuzional se observă o creştere semnificativă a oxigenării tisulare cerebrale (CrSO2) chiar în timpul transfuziei, efect ce se menţine timp de 24 de ore: medie CrSO2 $80 \pm 2$, p value 0,019 . De asemenea valorile fracţiei de extracţie a oxigenului tisular cerebral încep să scadă în timpul transfuziei, şi se menţin scăzute şi în următoarele 24 de ore $0,22 \pm 0,05$ vs $0,15 \pm 0,02$ $-p$ value $<0,013$.

Concluzii. Transfuzia de CE la prematurii cu greutate foarte mică stabili clinic are ca rezultat creşterea tranzitorie a $\mathrm{CrSO} 2$ şi scăderea tranzitorie a FTOE. Putem folosi fracţia de eliberare a oxigenului tisular - FTOE - ca indicator al nevoii de transfuzie alături de valoarea hematocritului şi semnele clinice.
\end{abstract}

Cuvinte cheie: anemia prematurului, transfuzie CE, saturaţie tisulară cerebrală (CrSO2), fracţie de eliberare a oxigenului tisular (FTOE)

\section{INTRODUCERE}

În ultimii ani, măsurarea oxigenării regionale tisulare (rSO2) prin spectroscopie cu infraroşu (NIRS) a devenit din ce în ce mai frecventă în unitățile de terapie intensivă neonatală. NIRS a fost utilizată în mai multe situații clinice pentru a examina oxigenarea cerebrală a prematurilor Sunt studii care au utilizat saturația regională cerebrală $\mathrm{CrSO} 2$ ca biomarker pentru necesitatea transfuziei cu concentrat eritrocitar, precum şi răspunsul oxigenării cerebrale după transfuzie (1-3). O îmbunătățire a $\mathrm{CrSO} 2$ şi o reducere a fracției de extragere a oxigenului tisular cerebral C-FTOE au fost raportate după transfuziile cu CE. Unii investigatori au raportat o lipsă de corelație a hematocritului pretransfuzie cu $\mathrm{CrSO} 2$, sugerând că nivelul hematocritului este un predictor slab al oxigenării țesutu- rilor. S-a arătat că atât saturația regională cerebrală, cât şi cea periferică a oxigenului ( $\mathrm{CrSO} 2$, prSO2) scad atunci când capacitatea de transport a oxigenului este compromisă şi cresc în timpul transfuziei sanguine (4). Unii autori au investigat relația dintre numărul incidentelor hipoxice (IH) şi transfuzia de CE, urmând ipoteza că, dacă este disponibilă mai multă hemoglobină, transportul de oxigen este mai eficient, iar episoadele hipoxice pot fi prevenite $(5,6)$. O îmbunătățire semnificativă a CrSO2, prSO2, perfuziei şi simptomelor anemiei a fost descrisă după transfuzie la prematurii cu saturație cerebrală - CrS02 <55\% în comparație cu prematurii cu crSO2 $>55 \%$ (7-9). În acest studiu, am investigat dacă măsurătorile NIRS înainte şi după transfuziile cu CE pot răspunde la întrebarea: a reprezentat transfuzia un beneficiu? Pot fi măsurătorile derivate din NIRS utile în identificarea unor criterii mai 
obiective pentru ghidurile de transfuzie? Am emis ipoteza că măsurarea saturației cerebrale $(\mathrm{CrSO} 2)$ cu ajutorul NIRS este posibil să selecteze prematurii care vor avea cel mai mare beneficiu clinic după transfuzia de $\mathrm{CE}$. Monitorizarea $\mathrm{CrSO} 2$ ar putea detecta semnele subclinice ale dezechilibrului dintre livrare-consum al O2 (adică FTOE crescut) care nu poate fi detectat utilizând monitorizarea convențională (de exemplu examen fizic, semne vitale, pulsoximetrie, hematocrit). La prematurii nontransfuzați monitorizați la o vârstă postnatală echivalentă ar trebui să obținem semnale NIRS comparabile cu valorile de referință normale pentru vârstă, permițându-ne astfel să atribuim modificările evenimentului de transfuzie.

\section{MATERIAL ŞI METODĂ}

Acest studiu prospectiv, observaţional şi nonintervențional s-a derulat într-un centru terțiar de terapie intensivă neonatală în intervalul iulie 2017 martie 2018. Protocolul NIRS a presupus completarea unor date de monitorizare a prematurilor cu risc major de anemie şi transfuzie de CE. Criteriile de includere au vizat prematurii cu $\mathrm{VG} \leq 30 \mathrm{de}$ săptămâni şi cu greutate la naştere $\leq 1.250 \mathrm{~g}$. Au fost excluşi nou-născuții cu greutate la naştere $<500 \mathrm{~g}$, anomalii congenitale/cromozomiale majore, scor Apgar <3 la 5 minute, hemoragia intraventriculară gradele 3-4. Pacienţii au fost înscrişi în primele 72 de ore după naştere şi au fost monitorizați continuu pe parcursul internării. Monitorizarea a inclus: monitorizare continuă cardiorespiratorie şi pulsoximetrie convențională; evaluare hematologică săptămânală: hemoglobină, hematocrit, indici eritrocitari, sideremie; curbele calorice şi antropometrice. Înainte şi după transfuzie a fost monitorizat EAB din analiza gazelor sanguine (AGS) din care s-au extras valorile pentru $\mathrm{pH}$ şi lactat seric la toți prematurii din studiu.

Prematurii care au necesitat transfuzie au fost monitorizați în plus cu metoda de evaluare a oxigenării regionale cerebrale NIRS, pretransfuzional (monitorizare continuă 24 de ore), în timpul transfuziei, şi 24 de ore după transfuzie. Pacienții netransfuzați au fost de asemenea monitorizați cu pulsoximetrie regională cerebrală în momentul în care erau stabili respirator şi hemodinamic, alimentație enterală completă, curbe ponderale în creştere la o vârstă postnatală şi în condiții clinice asemănătoare grupului transfuzat. Monitorizarea saturației cerebrale, $\mathrm{CrSO} 2$ a fost instituită utilizând oximetrul cerebral/somatic FORE SIGHT ELITE. În studiile pediatrice cu acest dispozitiv, precizia situsului ce- rebral cu senzorul small a fost de $-0,01 \pm 5,38 \%$ şi $0,03 \pm 5,69 \%$ pentru situsurile non-cerebrale (10). Variabilele absolute măsurate de NIRS în timpul monitorizării: saturația regională cerebrală: $\mathrm{CrSO} 2$ şi fracția de extracție a oxigenului tisular cerebral: C-FTOE. Intervalul normal de referință pentru $\mathrm{CrSO} 2$ pentru prematuri variază între $55 \%$ şi $85 \%$ în funcție de factori cum ar fi tipul aparatului, starea clinică şi vârsta postnatală. Sunt studii în care s-a constatat o corelație negativă semnificativă între $\mathrm{CrSO} 2$ şi vârsta gestațională ( $\mathrm{r} 1 / 4 \quad 0,77$; $\mathrm{P}<0,001)$. Cel mai mare nivel de $\mathrm{CrSO} 2$ şi cel mai mic C-FTOE au fost găsite între 30 şi 33 săptămâni; ulterior, $\mathrm{CrSO} 2$ a scăzut progresiv, iar C-FTOE a crescut, atingând valoarea minimă la 38-39 săptămâni. În aceste studii CrSO2 s-a corelat, de asemenea, semnificativ cu ritmul cardiac, rata respiratorie şi valorile $\mathrm{SaO} 2$ (r 1/4 0,65; P <0,001) (11-13). În studiul nostru am fixat ca interval normal de referinţă la prematurul sub 32 de săptămâni şi peste 7 zile valorile de $71 \pm 7 \%$ (14). Toți pacienții au fost îngrijiți în conformitate cu strategii predefinite de ventilație, fluide şi electroliţi şi protocoale de alimentație. Ecocardiografia de screening a fost efectuată pentru toți pacienții la 3-5 zile de viață şi acei subiecți cu canal arterial (PDA) semnificativ hemodinamic au fost tratați cu ibuprofen.

\section{Transfuziile de concentrat eritrocitar (CE)}

$\mathrm{Au}$ fost administrate în funcție de valorile hemoglobinei şi hematocritului, dar raportate la vârsta postnatală, statusul respirator şi semne clinice asociate. Nu au fost incluşi în această analiză pacienții care au primit transfuzii cu CE pentru pierderea hemoragică de sânge (de exemplu hemoragie intraventriculară), studiul fiind axat pe detectarea modificărilor parametrilor de oxigenare cerebrală la subiecții VLBW stabili.

\section{Colectarea şi analiza datelor}

Informaţiile demografice au fost extrase din diagramele pacientului concomitent cu măsurătorile NIRS.Rezultatele analizelor de laborato efectuate la fiecare 7 zile au fost incluse în monitorizare. Subiecții non-transfuzați au fost monitorizați NIRS timp de 12 ore, la aproximativ 35 zile postnatal, aceasta reprezentând mediana de vârstă postnatală la care s-a efectuat prima transfuzie la grupul transfuzat. S-au efectuat comparații între grupuri utilizând testele t Student şi studiile Chi- squared pentru date nonparametrice; $\mathrm{P}<0,05$ a fost utilizat pentru a desemna semnificația statistică pentru toate analizele. Pentru analiza rezultatelor oxigenării 
cerebrale pre-, în timpul şi posttransfuzie, s-au folosit testele Kruskal Wallis şi Mann Whitney U test, pentru a calcula magnitudinea efectului transfuziilor asupra $\mathrm{CrSO} 2$ şi C-FTOE (effect size).

\section{REZULTATE}

Pentru ancheta generală NIRS, inițial au existat 57 de nou-născuţi eligibili între iulie 2017 şi martie 2018, cu vârsta de gestație mai mare de 30 săptămâni şi greutate la naştere între $500 \mathrm{~g}$ şi $1.250 \mathrm{~g}$, dintre care $44(77 \%)$ au îndeplinit criteriile de înscriere şi au încheiat protocolul de monitorizare. Motivele nonincluderii au fost: refuzul consimțământului $(n=2)$, hemoragie intraventriculară $>$ gr. 3 $(n=3)$, deces $(n=3)$ şi indisponibilitatea echipamentului $(\mathrm{n}=5)$. Selecția subiecților a condus la 44 nounăscuți stabili și previzibili din punct de vedere clinic. Dintre aceştia, 29 prematuri $(66 \%)$ au efectuat cel puțin o transfuzie în timpul internării, iar întregul grup a primit un număr de 57 de transfuzii, media transfuziilor/copil fiind de 1,9 $\pm 1,3$. Grupul de comparație $(n=15)$ al nou-născuților netransfuzați a avut o vârstă gestațională mai mare $(28,5 / 26,2$ spt.), o greutate la naştere mai mare $1.154 \pm 195 / 941 \pm 227$ g, patologie de sarcină mai redusă şi o probabilitate mai redusă de intubare în sala de naştere comparativ cu subiecții transfuzați $(p<0,05)$. Valorile hemoglobinei şi hematocritului, asociate cu semnele clinice de anemie $(59 \%, \mathrm{n}=17)$, au fost motivele principale ale terapiei transfuzionale cu concentrat eritrocitar. În grupul transfuzat prima transfuzie a fost efectuată în medie în a 35 -a zi $(35,8 \pm 18,3 ; 10-72)$ şi pentru acest motiv între cele două grupuri s-au comparat mediile valorilor hematologice din probele recoltate în a 5-a săptămână postnatal. Nu au existat diferențe semnificative între valorile hemoglobinei, hematocritului şi ale indicilor eritrocitari.

\section{Rezultatele oxigenării regionale cerebrale (NIRS)}

Valorile oximetriei cerebrale şi sistemice au avut valori comparabile la cele cele două grupuri atunci când s-au comparat rezultatele dinaintea efectuării transfuziei şi corespund cu valorile normale de referință la prematurii sub 32 de săptămâni şi peste 7 zile de viață - Tabelul 1 (14). Nu s-au demonstrat modificări semnificative statistic în saturația cerebrală $-\mathrm{CrSO} 2$ sau în fracția de eliberare a oxigenului tisular cerebral - C-FTOE în grupul de comparație non-transfuzat pe o vârstă echivalentă postnatală şi pe o perioadă de observație de 12 ore. Legat de efectul transfuziilor rezultatele au demonstrat o creştere semnificativă a oxigenării tisulare cerebrale $(\mathrm{CrSO} 2)$ chiar în timpul celor 4 ore de monitorizare din timpul transfuziei, $73 \pm 2$ vs $75 \pm 6$, efect ce se menține timp de 24 de ore post-transfuzional: medie $\mathrm{CrSO} 2$ post $\mathrm{T}=80 \pm 2$, p value 0,019 . De asemenea valorile fracției de extracție a oxigenului tisular cerebral încep să scadă în timpul transfuziei şi se mențin scăzute şi în următoarele 24 de ore $0,25 \pm 0,05$ vs $0,15 \pm 0,02-p$ value 0,013 (Tabelul 2, Fig. 1 şi 2). Nu s-au observat modificări semnificative ale indicelui de perfuzie tisulară şi ale lactatului seric între cele două grupuri şi pre/posttransfuzional.

TABELUL 1. Rezultatele monitorizării saturației cerebrale la cele două grupuri înainte de transfuzie

\begin{tabular}{|l|c|c|c|}
\hline Variabile* & $\begin{array}{c}\text { Transfuzați } \\
(\mathbf{n = 2 9 )}\end{array}$ & $\begin{array}{c}\text { Netransfuzați } \\
(\mathbf{n = 1 5 )}\end{array}$ & P value \\
\hline spO2 & $94 \pm 3$ & $93 \pm 5$ & 0.98 \\
\hline CrSO2 & $73 \pm 2.6$ & $72 \pm 3.6$ & 0.26 \\
\hline C-FTOE & $0.25 \pm 0.05$ & $0.23 \pm 0.02$ & 0.83 \\
\hline Seric Lactat & $1.28 \pm 0.2$ & $1.2 \pm 0.1$ & 0.61 \\
\hline Perfusion Index & $1.2 \pm 0.3$ & $1.3 \pm 0.5$ & 0.5 \\
\hline pH (median $\pm D S)$ & $7.33 \pm 0.06$ & $7.31 \pm 0.03$ & 0.25 \\
\hline
\end{tabular}

*(median $\pm \mathrm{DS}) \mathrm{CrSO} 2=$ saturaţia regională cerebrală a oxigenului; C-FTOE = fracţia de extracţie a oxigenului tisular

\section{DISCUŢII}

Transfuziile de CE administrate la prematurii cu greutate foarte mică la naştere stabili hemodinamic şi respirator au crescut valorile saturației regionale cerebrale $(\mathrm{CrSO} 2)$ şi au redus fracția de extracție a

TABELUL 2. Efectul transfuziilor asupra parametrilor de oxigenare şi eliberare a oxigenului la nivel cerebral

\begin{tabular}{|l|c|c|c|c|}
\hline Variabile* & $\begin{array}{c}\text { Pre-transfuzie CE (24 } \\
\text { ore) }\end{array}$ & $\begin{array}{c}\text { Transfuzie CE } \\
\text { (4 ore) }\end{array}$ & $\begin{array}{c}\text { Post-transfuzie CE } \\
\text { (24 ore) }\end{array}$ & P value \\
\hline SpO2 (\%) & $94 \pm 3 / 94,78$ & $94 \pm 4 / 94,52$ & $94 \pm 2 / 94,71$ & 0,82 \\
\hline CrSO2 & $73 \pm 2 / 72,66$ & $75 \pm 1,5 / 74,94$ & $80 \pm 2 / 79,74$ & 0,019 \\
\hline C-FTOE & $0,25 \pm 0,05$ & $0,19 \pm 0,04 / 0,21$ & $0,15 \pm 0,02 / 0,15$ & 0,013 \\
\hline Lactatul seric & $1,28 \pm 0,2 / 0,23$ & - & $1,4 \pm 0,3$ & 0,5 \\
\hline Index de perfuzie sulară & $1,2 \pm 0,3$ & - & $1,1 \pm 0,3$ & 0,8 \\
\hline pH (median $\pm D S)$ & $7,33 \pm 0,06$ & - & $7,30 \pm 0,03$ & 0,63 \\
\hline
\end{tabular}

*median $\pm \mathrm{DS} ; \mathrm{CrSO}=$ oxigenare regională tisulară cerebrală; C-FTOE = fracţia de extragere a oxigenului tisular cerebral. $p<0.05$ pentru toate saturaţiile $\mathrm{CrSO} 2$ și FTOE pre-post calculate ${ }^{* *}$ (Kruskal Wallis Test) 


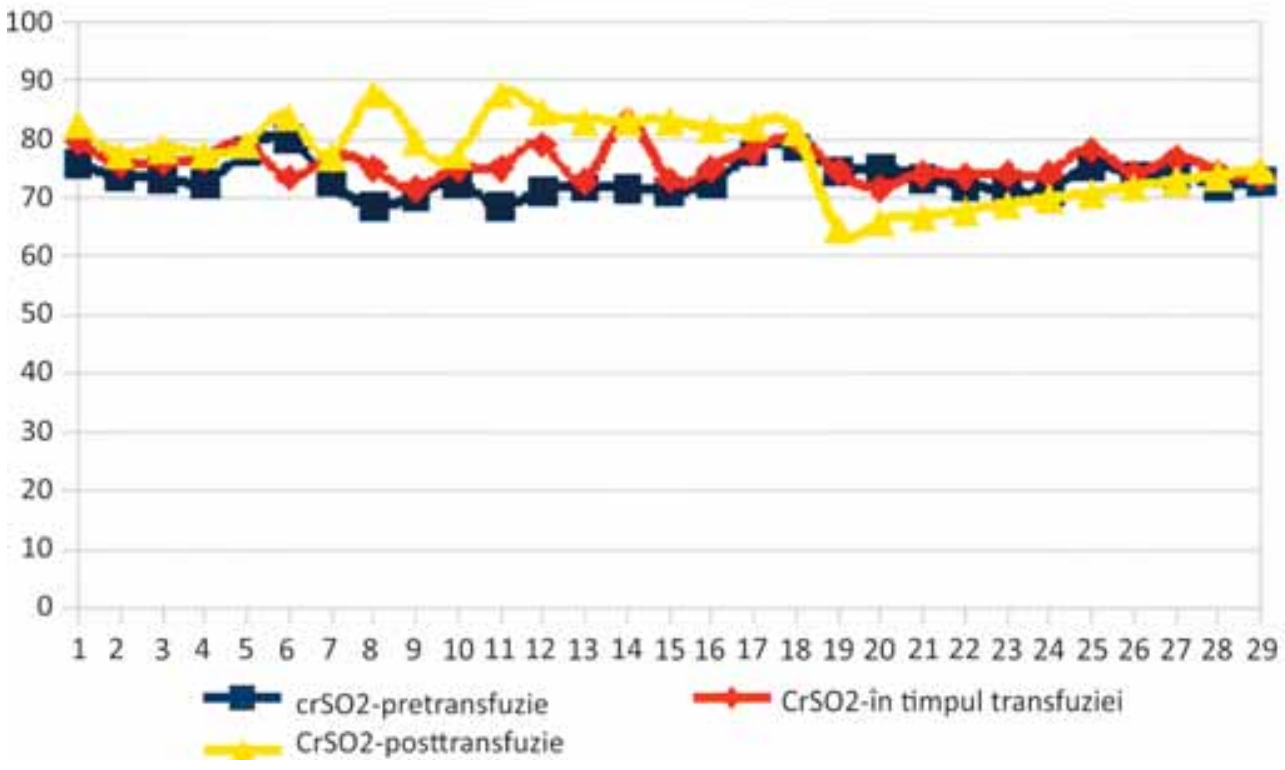

FIGURA 1. Efectul transfuziilor asupra oxigenării cerebrale (curbele CrSO2)

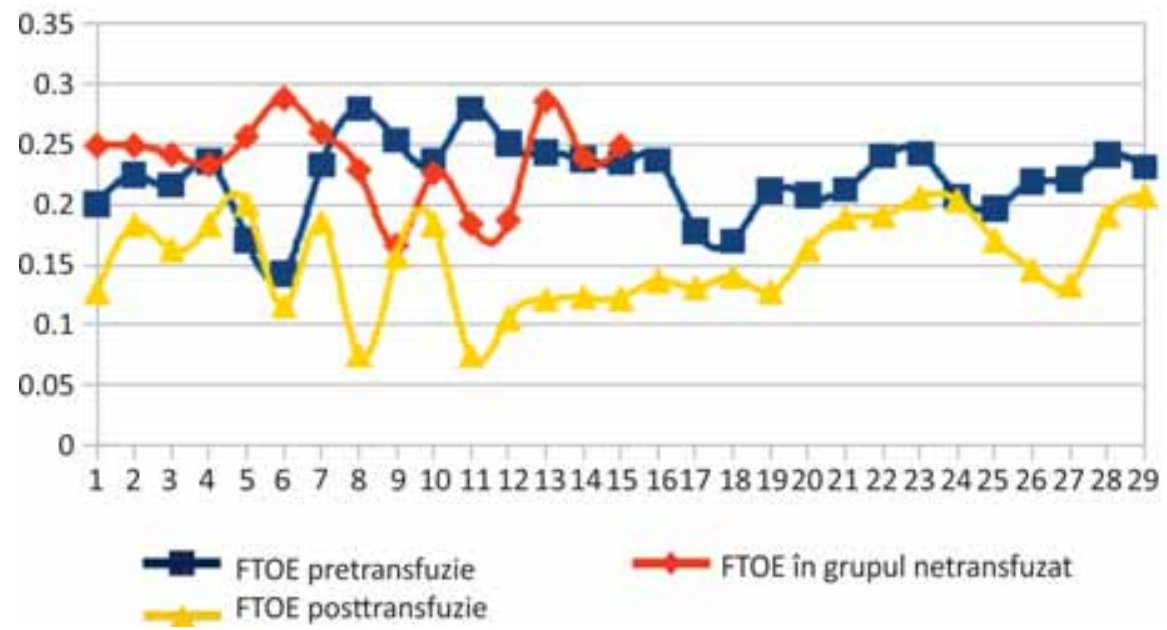

FIGURA 2. Curbele fracției de extracție a oxigenului tisular

oxigenului tisular cerebral (C-FTOE) aşa cum era de aşteptat în cazul prezenței anemiei $(2,8,9)$. La subiecții transfuzați nu s-au observat modificări semnificative statistic ale măsurătorilor convenționale ale oxigenării cum ar fi saturația pulsatilă a oxigenului capilar ( $\mathrm{SpO} 2)$, indicele de perfuzie tisulară, lactatul $(15,16)$. Deoarece hemoglobina este principalul determinant al furnizării de oxigen, aceste constatări susțin argumentul că, în condițiile în care eliberarea oxigenului poate deveni limitată (anemie), schimbările măsurabile în extracția oxigenului apar la nivel tisular înainte de apariția semnelor clinice reale (17) sugerând ca FTOE poate fi o măsurătoare mai sensibilă a modificărilor oxigenării. Într-un studiu prospectiv efectuat în anul 2002 care a încercat să utilizeze FTOE pentru identificarea nevoii de transfuzie (18), extracția de oxi- gen a scăzut (adică s-a îmbunătățit) după transfuzia de CE pentru fiecare dintre indicațiile clinice utilizate. În studiul nostru nu am observat modificări ale metabolismului tisular ( $\mathrm{pH}$, acid lactic) la copiii anemici şi nici modificări ale indicelui de perfuzie tisulară înainte sau după transfuzie. Concentrația lactatului seric a fost intens utilizată la prematuri ca un criteriu pentru transfuzia de concentrat eritrocitar în anemie şi corelată puternic cu rezultatul transfuziei (19).

Deoarece am studiat efectele anemiei şi ale efectelor transfuziei la prematuri stabili hemodinamic, efectele metabolice nu au fost observate datorită existenței unei capacități de rezervă suficiente pentru a satisface cererile metabolice. Trebuie notat faptul că concentrația serică a lactatului nu se corelează întotdeauna cu perfuzia tisulară. Ficatul este 
principalul organ care metabolizează acidul lactic în exces produs la nivel tisular. Există tulburări tranzitorii ale metabolismului aminoacizilor la prematuri care pot da alte nivele de acid lactic independent de perfuzia tisulară (20).

O limitare a studiului nostru este că, deşi am examinat un subgrup extrem de selectat, omogen de prematuri stabili, ar fi necesar un eşantion mai mare care să urmărească în paralel şi alte situsuri de oxigenare tisulară (splahnică, renală), ce ar putea da mai multă încredere în relevanța clinică imediată a constatărilor noastre. Astfel, această analiză este utilă în primul rând pentru generarea ipotezei că utilizând fie FTOE, fie rSO2 se pot stabili mai corect pragurile de transfuzie pe baza unei evaluări mai directe a oxigenării țesuturilor. În rezumat, acest studiu arată că o transfuzie de CE la prematurii cu greutate foarte mică stabili clinic are ca rezultat creşterea tranzitorie a $\mathrm{CrSO} 2$ şi scăderea tranzitorie a FTOE şi nicio modificare a pH-ului, lactatului seric sau a saturației sistemice a oxigenului. Datele noastre sprijină utilizarea măsurătorilor derivate din NIRS (FTOE) în identificarea dezechilibrului subclinic de livrare-consum al $\mathrm{O} 2$ la prematurii anemici.

\section{CONCLUZII}

Putem folosi fracția de eliberare a oxigenului tisular - FTOE - ca indicator al nevoii de transfuzie alături de valoarea hematocritului şi semnele clinice. În studiul nostru, o fracție de extracție a oxigenului (C-FTOE) pretransfuzie $>0,25$ şi asocierea de semne clinice de anemie au demonstrat că transfuzia a fost bine aleasă ca modalitate de terapie.

Pentru ca măsurătorile derivate din NIRS să poată fi incluse în ghidurile de transfuzie sunt necesare mai multe studii eventual multicentrice pentru a stabili valorile limită ale FTOE peste care se indică transfuzia la cei cu anemie simptomatică. 